\title{
lodine Deficiency Disorder Among Filipino School Children, Pregnant and Lactating Women and the Elderly 20 Years After the Act for Salt Iodization Nationwide Law
}

\author{
Leah A. Perlas ${ }^{\mathrm{a}, \mathrm{c}}$, Joselita Rosario C. Ulanday ${ }^{\mathrm{b}}$, Juanita M. Marcos ${ }^{\mathrm{b}}$, Michael E. Serafico ${ }^{\mathrm{b}}$, \\ Josefina A. Desnacido ${ }^{b}$, Maritess V. Alibayan ${ }^{b}$, Charmaine A. Duante ${ }^{b}$, Mario V. Capanzana ${ }^{b}$
}

\begin{abstract}
Background: Iodine deficiency disorder (IDD) is still a public health problem globally. In response to this, universal salt iodization (USI) has been implemented. This is the most cost-effective strategy to prevent and control it. In the Philippines, an Act for Salt Iodization Nationwide (ASIN Law) was passed in 1995, in response to the increasing goiter rates. This paper describes the prevalence and severity of IDD among Filipino school-aged children (SAC), pregnant and lactating women and the elderly, 20 years after the implementation of the ASIN Law.
\end{abstract}

Methods: Casual urine samples were collected from SAC, pregnant and lactating women and elderly of 1998, 2003, 2008 and 2013, of selected households of the National Nutrition Survey (NNS). Urinary iodine (UI) levels were determined using the acid digestion method. UI levels and prevalence of IDD in the 2013 NNS were compared with those in previous NNSs.

Results: Iodine nutrition among the SAC has improved from mild deficiency with a median of $71 \mu \mathrm{g} / \mathrm{L}$ in 1998 to $201 \mu \mathrm{g} / \mathrm{L}$ in 2003 . It has remained "optimal" till the 2013 NNS, almost 20 years after ASIN Law. UI was $107 \mu \mathrm{g} / \mathrm{L}$ among the elderly in 2008, but decreased to $80 \mu \mathrm{g} / \mathrm{L}$ in 2013 , also indicating "mild" iodine deficiency. Among the lactating women, UI was $111 \mu \mathrm{g} / \mathrm{L}$ in 2003, indicating iodine sufficiency, but decreased to 81 and $77 \mu \mathrm{g} / \mathrm{L}$ in 2008 and 2013 NNS, respectively, indicating "mild" iodine deficiency. Median UI among the pregnant women was 142,105 and $105 \mu \mathrm{g} / \mathrm{L}$, also indicating the presence of IDD for the 2003, 2008 and 2013 NNS, respectively.

Conclusion: Twenty years after ASIN Law, Filipino SAC have

Manuscript submitted April 24, 2017, accepted May 12, 2017

${ }^{a}$ Food and Nutrition Research Institute, Gen. Santos Ave., Bicutan, Taguig City, Philippines

bepartment of Science and Technology, Food and Nutrition Research Institute, Taguig City, Philippines

${ }^{c}$ Corresponding Author: Leah A. Perlas, Food and Nutrition Research Institute, Gen. Santos Ave., Bicutan, Taguig City, Philippines.

Email: perle571@yahoo.com

doi: https://doi.org/10.14740/jem414w achieved optimum iodine status while the pregnant and lactating women and the elderly remain to be iodine deficient. Strict monitoring of iodization of salt at the production site should be implemented, since iodine levels in salt have remained at levels below the standard.

Keywords: Filipinos; School-aged children; Pregnant; Lactating; Elderly; Iodine deficiency disorder; ASIN Law

\section{Introduction}

Universal salt iodization (USI) is the most cost-effective strategy to prevent and control iodine deficiency disorders (IDDs). In the Philippines, in 1995, an Act Promoting Salt Iodization Nationwide and for Related Purposes (ASIN Law) was passed because of the increasing goiter rates [1]. This law requires all salt producers and manufacturers to iodize the salt they manufacture, distribute, trade and/or import.

Globally, the continued decrease in IDD is being attributed to USI. Based on urinary iodine excretion (UIE) levels of school-aged children (SAC) as proxy indicator for the population, the number of iodine deficient countries has decreased from 54 in 2003, to 47 in 2007, 32 in 2011 and 25 in 2014 [2]. Coinciding with the decrease in IDD is the increase in urinary iodine (UI) levels corresponding to excessive iodine intake. There were only five countries with excessive intakes in 2003 and this steadily increased to 12 countries in 2014 [2]. This can happen in countries with chronic iodine deficiency, because there is a rapid increase in iodine intake from iodized salt [3].

Certain Asian countries have attributed improvement of iodine status of their populations to USI. After 10 years of USI in China, iodine nutrition of children 8 - 10 years old improved [4]. In 1995, UIE level was $119.9 \mu \mathrm{g} / \mathrm{L}$ and increased to 191.8 $\mu \mathrm{g} / \mathrm{L}$ in 2005 . As well, there was a decrease in total goiter rate (TGR) and increase in intelligence quotient (IQ). In Peninsular Malaysia [5], median UI was $82 \mu \mathrm{g} / \mathrm{L}$ in a 1996 survey as compared to $104.1 \mu \mathrm{g} / \mathrm{L} 10$ years after the implementation of Malaysian Food Act of 1983. The same trend was reported in Bangladesh [6].

Iodine deficiency is the leading cause of preventable mental retardation and impaired psychomotor function in young children. It results in a lower IQ up to 13.5 points below that 
Table 1. Epidemiological Criteria for Assessment of lodine Nutrition in a Population Based on Median or Range of Urinary lodine Concentration in School-Aged Children $\left(\geq 6\right.$ Years) ${ }^{\star}$

\begin{tabular}{lll}
\hline Median UIE $(\boldsymbol{\mu g} / \mathbf{L})$ & Iodine intake & Iodine nutrition \\
\hline$<20$ & Insufficient & Severe iodine deficiency \\
$20-49$ & Insufficient & Moderate iodine deficiency \\
$50-99$ & Insufficient & Mild iodine deficiency \\
$100-199$ & Adequate & Optimal \\
$200-299$ & More than adequate & Risk of iodine-induced hyperthyroidism in susceptible groups \\
$\geq 300$ & Excessive & Risk of adverse health consequences \\
\hline
\end{tabular}

*Applies to adults but not to pregnant women. WHO, UNICEF and ICCIDD, 2001.

of those without IDD. A meta-analysis of 87 studies worldwide showed that iodized salt increases IQ by an average of 8.18 points (97\% CI: $6.71-9.65)$ and UI concentration by an average of $59.22 \mu \mathrm{g} / \mathrm{L}(95 \% \mathrm{CI}: 50.40$ - 68.04) among children [7].

During pregnancy, it increases the risk of still birth and miscarriage. Irreversible impairment of brain development of the fetus occurs if there is iodine deficiency during the second and third trimester of pregnancy. Iodine is necessary for the synthesis of thyroid hormones which is required for the optimal development of the brain. During lactation, iodine deficiency results in low iodine concentrations in breastmilk.

This paper will present results of the series (1998, 2003, 2008 and 2013) of NNS of IDD before and after the implementation of the ASIN Law in 1995. It also aimed to assess the progress towards the elimination of IDD.

\section{Methods}

\section{Survey design}

The National Nutrition Survey (NNS) of the Philippines is conducted every 5 years by the Food and Nutrition Research Institute of the Department of Science and Technology (FNRIDOST). The 1998, 2003, 2008 and 2013 NNSs were one-time cross-sectional studies covering all regions of the country. A stratified multi-stage sampling design was used covering 17 regions and the national capital region (NCR). The first stage of sampling was the selection of primary sampling unit (PSU). A PSU is a barangay or contiguous barangays with at least 500 households, then, followed the selection of enumeration areas (EA), a contiguous area in a barangay or a barangay with 150 - 200 households. The final sampling unit was the household.

\section{Urine collection, field storage and transport}

In all the surveys, about $15 \mathrm{~mL}$ of mid-stream casual urine samples were collected from SAC 6 - 12 years, pregnant and lactating women and the elderly of the selected household. These were kept frozen in the field and while in transport to the
Biochemical Laboratory (BL) of FNRI. At the BL, the urine samples were stored in freezers until determination of UI was conducted.

\section{Determination of UI}

UI determination was conducted at the BL of the FNRI-DOST. The acid digestion method of Dunn et al [8] was used to determine UI concentrations. For quality assurance, the BL participates in the Ensuring Quality of Urinary Iodine Procedures (EQUIP) program of CDC, in Atlanta, USA. For precision, a pool of urine is prepared and UI level of the pool, whose concentration was previously determined was analyzed together with the survey samples.

\section{Ethics approval}

The conduct of the study was approved by the FNRI Institutional Ethics and Review Committee (FIERC). It was carried out in accordance with the Declaration of Helsinki, guided by the Council for International Organization of Medical Sciences Ethical Guidelines for Biomedical Research involving human subjects [9] and the National Guidelines for Biomedical/Behavioral Research [10]. Only those who signed the informed consent form were included in the study.

Written consent to participate in the eighth NNS was obtained from adult respondents and participants prior to the interview and other measurements. An assent form was accomplished by parents or guardians of children aged 7 years and below. The informed consent and assent forms were translated

Table 2. Epidemiological Criteria for Assessment of lodine Nutrition in a Population Based on Median or Range of Urinary lodine Concentration of Pregnant Women

\begin{tabular}{ll} 
Median UIE $(\boldsymbol{\mu g} / \mathrm{L})$ & Iodine intake \\
\hline$<150$ & Insufficient \\
$150-249$ & Adequate \\
$250-499$ & Above requirements \\
$\geq 500$ & Excessive \\
\hline
\end{tabular}

WHO, UNICEF and ICCIDD, 2007. 
Table 3. Median UIE and Percent Distribution by Age and Physiologic Groups: Philippines, 2013

\begin{tabular}{lllllllll}
\hline \multirow{2}{*}{ Age/physiologic group } & $\mathbf{n}$ & Median $(\boldsymbol{\mu g} / \mathbf{L})$ & \multicolumn{4}{c}{ UIE $(\boldsymbol{\mu g} / \mathbf{L})$} \\
\cline { 5 - 8 } & & & $\mathbf{2 0}$ & $\mathbf{2 0 - 4 9}$ & $\mathbf{5 0 - 9 9}$ & $\mathbf{1 0 0}-\mathbf{1 9 9}$ & $\mathbf{2 0 0}-\mathbf{2 9 9}$ & $\geq \mathbf{3 0 0}$ \\
\hline 6 - 12 years & 22,588 & 168 & 7.7 & 8.7 & 14.9 & 26.6 & 18.9 \\
Elderly & 3,676 & 80 & 15.0 & 18.7 & 24.0 & 27.6 & 8.9 & 23.2 \\
Lactating women & 1,460 & 77 & 15.6 & 18.6 & 24.8 & 26.0 & 10.3 & 4.7 \\
& & Median & $<20$ & $20-49$ & $50-149$ & $150-249$ & $250-499$ & $\geq 500$ \\
Pregnant women & 1,095 & 105 & 11.1 & 15.9 & 37.4 & 20.7 & 12.1 & 2.8 \\
\hline
\end{tabular}

into dialects that are most commonly spoken in the Philippines; it explained the background and objectives of the survey, the data collection procedures, involved risks and benefits of participation, confidentiality of information, option to withdraw without penalty or consequences, and the respondent's written consent.

\section{Data analysis and interpretation of results}

Descriptive statistics (medians and prevalence of deficiencies) were generated using Statistical Package for the Social Sciences (SPSS) Software, Version 16 (IBM Corp., Armon, NY). Weighting factors were computed and used to generate medians and prevalence rates for the different age and physiologic groups.

The severity of IDD for SAC, elderly, pregnant and lactating women based on median UI concentration was assessed using the epidemiological criteria set by ICCIDD and WHO
$[3,11]$ shown in Tables 1 and 2 .

\section{Results}

UI levels were determined as a measure of iodine deficiency in the 1998, 2003, 2008 and 2013 NNSs. According to WHO/ICCIDD/UNICEF [3], the indicator for iodine deficiency elimination is a median UI of more than $100 \mu \mathrm{g} / \mathrm{L}$, and not more than $20 \%$ of these values should be below $50 \mu \mathrm{g} / \mathrm{L}$.

In 2013, median UI level of the SAC was $168 \mu \mathrm{g} / \mathrm{L}$ (P20$80 \mathrm{th}, 63-322 \mu \mathrm{g} / \mathrm{L})$ and proportion of UI level $<50 \mu \mathrm{g} / \mathrm{L}$ was $<16.4 \%$ (95\% CI: $15.7-17.1$ ), indicating that iodine nutrition for these groups is optimal (Table 3). This indicates sufficient or adequate iodine intake for the above age groups. On the other hand, median UI level among the elderly was $80 \mu \mathrm{g} / \mathrm{L}$ (P2080th, 27 - 168) and lactating mothers was $77 \mu \mathrm{g} / \mathrm{L}$ (P20-80th, 31.7 - 36.9), indicating mild iodine deficiency corresponding to insufficient iodine intake. IDD for these groups is a mild

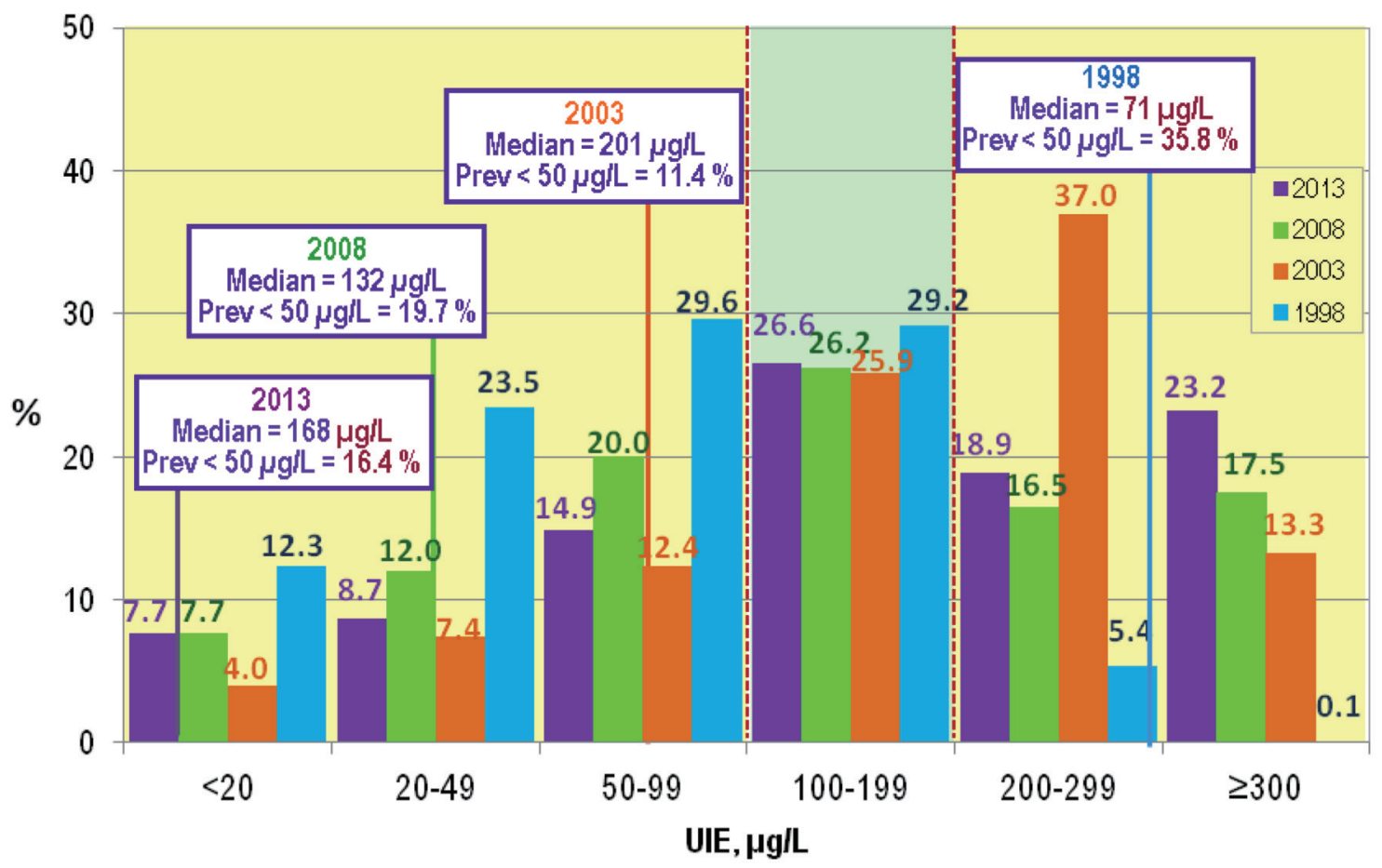

Figure 1. Frequency distribution of UIE values among 6 - 12 years old children, NNS 1998, 2003, 2008 and 2013: Philippines. 


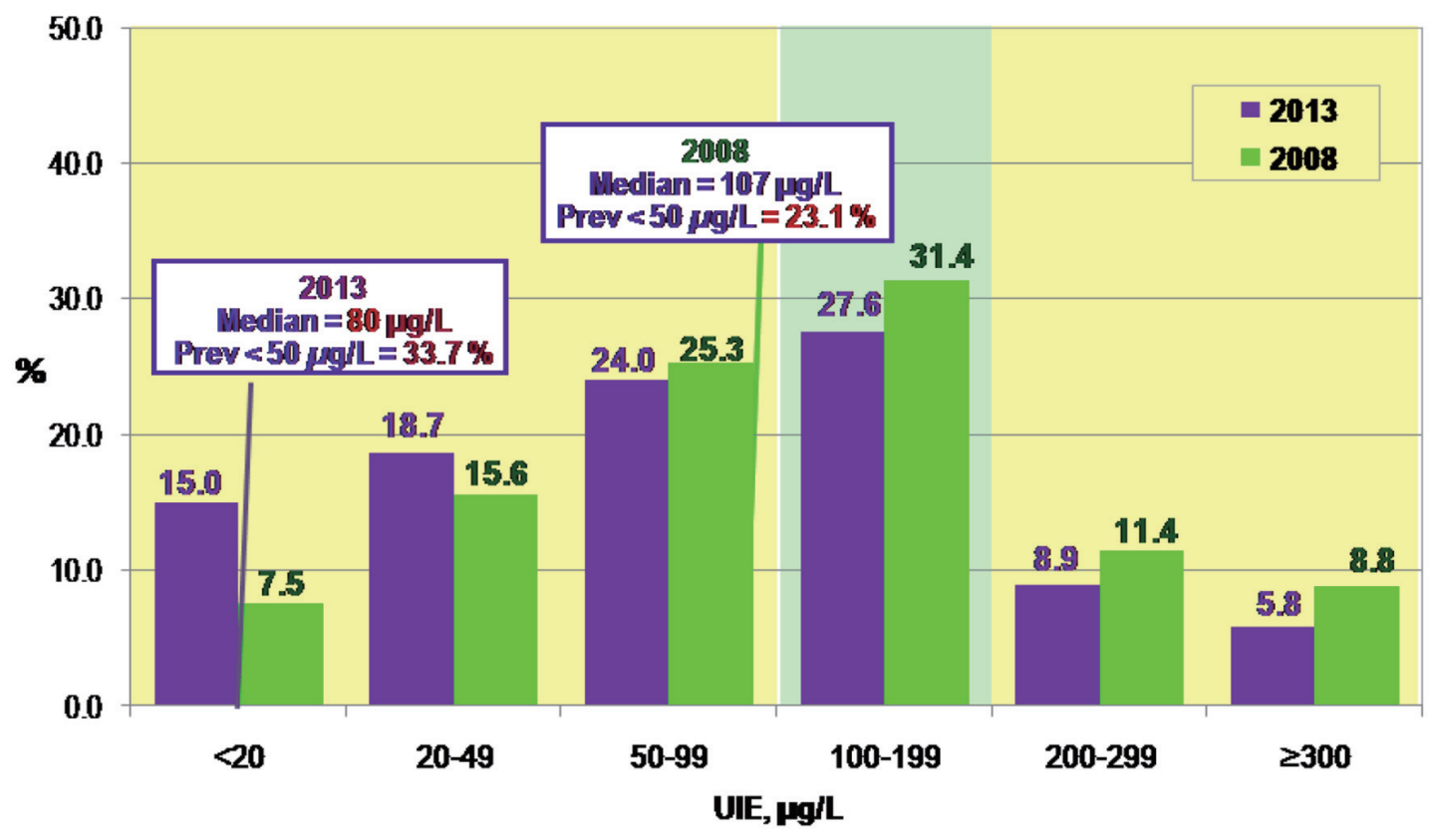

Figure 2. Frequency distribution of UIE values among elderly, NNS 2008 and 2013: Philippines.

public health problem. The cut-off for IDD among pregnant women is $150 \mu \mathrm{g} / \mathrm{L}$. Thus, the median UI of $105 \mu \mathrm{g} / \mathrm{L}$ (P2080th, $34-213)$ and the proportion for the pregnant women with UI $<50 \mu \mathrm{g} / \mathrm{L}$ of $27 \%$ (95\% CI: 24.1 - 29.8) indicate iodine deficiency.

Median UI levels indicating excessive iodine intake $(\geq$ $300 \mu \mathrm{g} / \mathrm{L}$ ) were highest among the SAC at $23.2 \%$. Among the pregnant women, median UI levels indicating excessive iodine intake $(\geq 500 \mu \mathrm{g} / \mathrm{L})$ were present in $2.8 \%$.

\section{Trend of IDD among SAC 6 - 12 years old}

UI of the SAC was determined in the 1998, 2003, 2008 and 2013 NNSs. Median UI in the 1998 NNS was $71 \mu \mathrm{g} / \mathrm{L}$ corresponding to mild IDD prevalence (Fig. 1). Value $<50 \mu \mathrm{g} / \mathrm{L}$ was $35.8 \%$. In the $2003 \mathrm{NNS}$, there was a significant increase in the median UI to $201 \mu \mathrm{g} / \mathrm{L}, 132 \mu \mathrm{g} / \mathrm{L}$ in 2008 , but increased to $168 \mu \mathrm{g} / \mathrm{L}$ in 2013. All the 2003, 2008 and 2013 median levels corresponded to optimum iodine nutrition. Levels $<50$ $\mu \mathrm{g} / \mathrm{L}$ were $11.4 \%, 19.7 \%$ and $16.4 \%$ in 2003,2008 and 2013 NNS, respectively.

UI levels $<100 \mu \mathrm{g} / \mathrm{L}$ indicating iodine deficiency were $65.4 \%, 23.8 \%, 39.7 \%$, and $31.3 \%$ for the 1998, 2003, 2008 and 2013, respectively. Excessive level $>300 \mu \mathrm{g} / \mathrm{L}$ was found to have steadily increased from $0.1 \% 1998$ to $23.2 \%$ in 2013 .

\section{Trend of IDD among the elderly}

UI was determined among the elderly only in the 2008 and 2013 NNSs. Median UI was $107 \mu \mathrm{g} / \mathrm{L}$ in 2008 but decreased to $80 \mu \mathrm{g} / \mathrm{L}$ in 2013 (Fig. 2). UI values $<50 \mu \mathrm{g} / \mathrm{L}$ were $23.1 \%$ and
$33.7 \%$ in 2008 and 2013, respectively, indicating the presence of IDD for both surveys. Adequate value was $31.4 \%$ in 2008 and decreased to $27.6 \%$ in 2013 . Values indicating excessive intake was $5.8 \%$ and $8.8 \%$ for the 2008 and 2013 , respectively.

\section{Trend of IDD among lactating mothers}

UI of the lactating women was determined in the 2003, 2008 and 2013 NNSs. Median UI was $111 \mu \mathrm{g} / \mathrm{L}$ in 2003 but decreased to $81 \mu \mathrm{g} / \mathrm{L}$ in 2008 which further decreased to $77 \mu \mathrm{g} / \mathrm{L}$ in 2013 (Fig. 3). Both the 2008 and 2013 levels were indicative of insufficient iodine status indicating IDD. UI values < $50 \mu \mathrm{g} / \mathrm{L}$ of $23.7 \%, 34.0 \%$ and $34.2 \%$ for 2003,2008 and 2013 NNS also indicate the presence of IDD, respectively.

UI values corresponding to insufficient $(<100 \mu \mathrm{g} / \mathrm{L})$ iodine intake among the lactating mothers were $46.4 \%, 59.5 \%$ and 59\% for the 2003, 2008 and 2013 NNS series, respectively. Adequate values (100 - $199 \mu \mathrm{g} / \mathrm{L})$ were $29.1 \%$ in 2003 , decreasing to $25.7 \%$ in 2008 and $26.0 \%$ in 2013. Above requirements $(200-299 \mu \mathrm{g} / \mathrm{L})$ were $21.1 \%$ in $2003,8.9 \%$ in 2008 and $10.3 \%$ in 2013 . Excessive values $(\geq 300 \mu \mathrm{g} / \mathrm{L})$ were also found; $3.6 \%$ in 2003, 5.8\% in 2008 and $4.7 \%$ in 2013 NNS.

\section{Trend of IDD among the pregnant women}

UI of the pregnant women was determined in the 2003, 2008 and 2013 NNSs. Median UI was $142 \mu \mathrm{g} / \mathrm{L}$ in 2003 but decreased to $105 \mu \mathrm{g} / \mathrm{L}$ in 2008 and 2013 (Fig. 4). Both values corresponded to deficient levels $(<150 \mu \mathrm{g} / \mathrm{L})$ for pregnant women. UI values $<50 \mu \mathrm{g} / \mathrm{L}$ were $18.0 \%$ and $25.8 \%$ for 2003 and 2008 , respectively. 


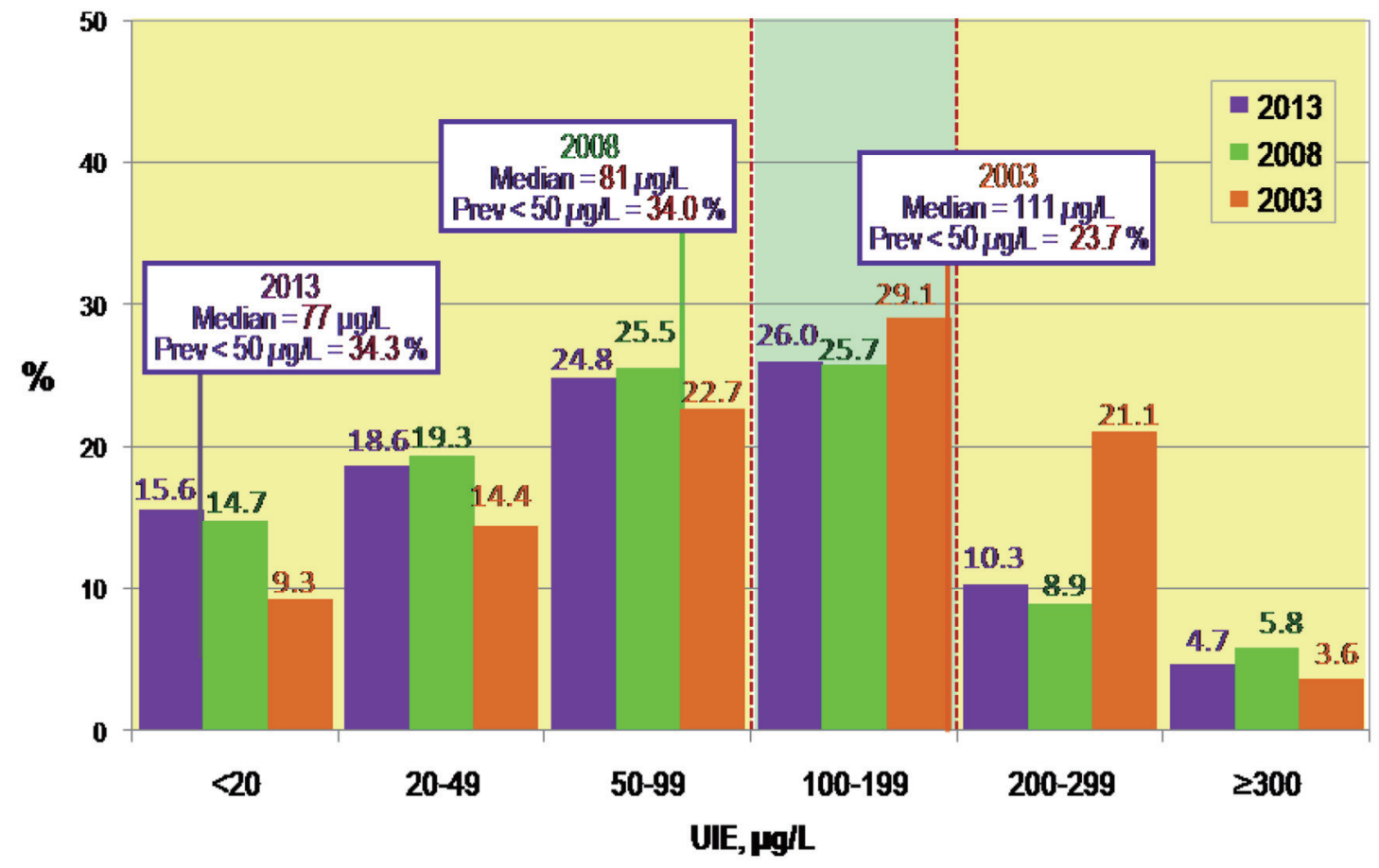

Figure 3. Frequency distribution of UIE values among lactating women, NNS 1998, 2003, 2008 and 2013: Philippines.

UI values $(<150 \mu \mathrm{g} / \mathrm{L})$ corresponding to insufficient iodine intake among the pregnant women levels were $52.0 \%$, $67.3 \%$ and $64.4 \%$ for the 2003,2008 and 2013 NNS series, respectively. Adequate values $(150-249 \mu \mathrm{g} / \mathrm{L})$ were $25.4 \%$ in 2003 , decreased to $18.1 \%$ in 2008 and increased to $20.7 \%$ in 2013. Above requirements $(250-499 \mu \mathrm{g} / \mathrm{L})$ were $22.5 \%$ in $2003,13.5 \%$ in 2008 and $12.1 \%$ in 2013 . There were no excessive values (>500 $\mu \mathrm{g} / \mathrm{L})$ in 2003 , but excessive values

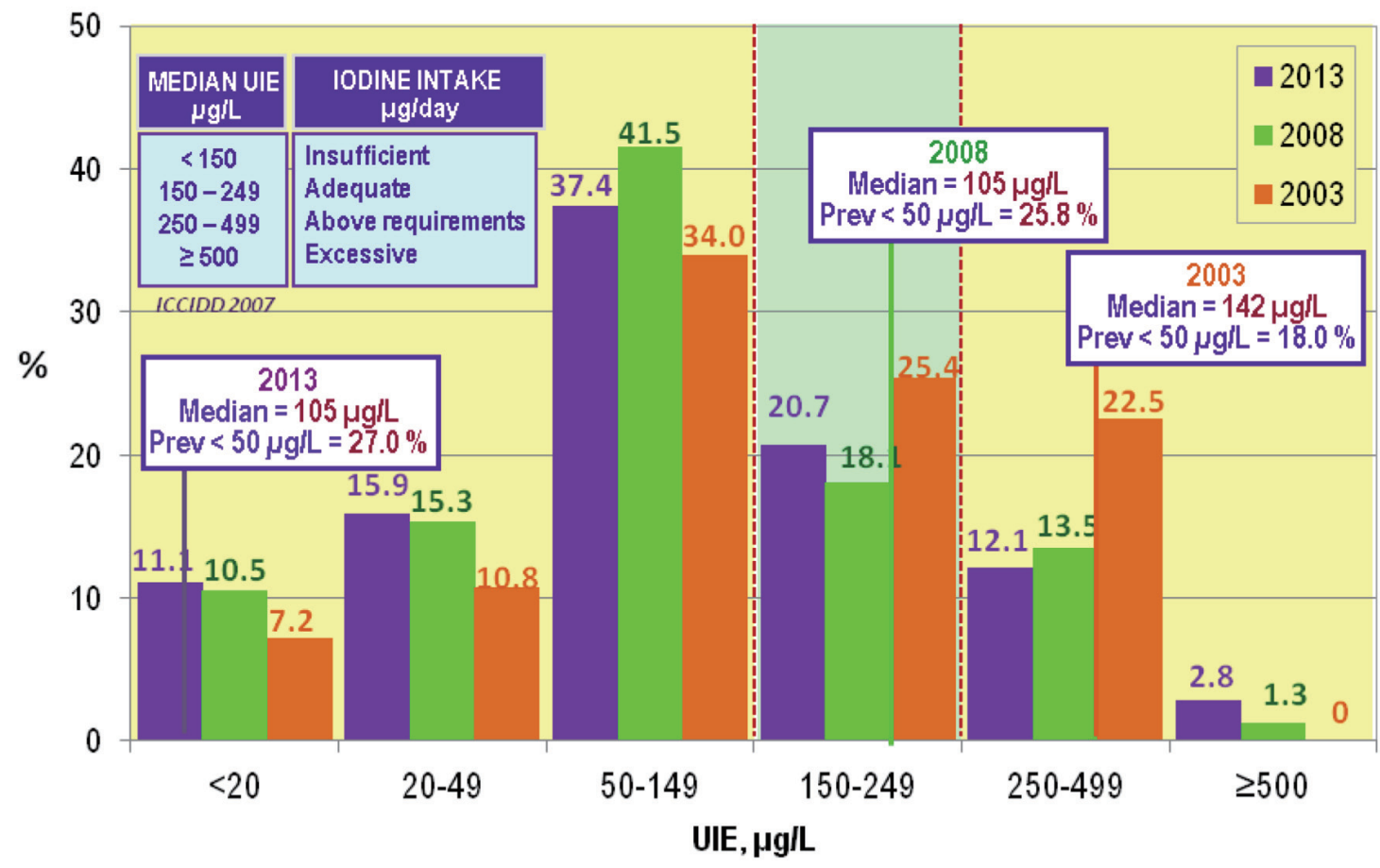

Figure 4. Frequency distribution of UIE values among pregnant women NNS 1998, 2003, 2008 and 2013: Philippines. 
Table 4. Progress Towards Elimination of IDD: Philippines 1998 to 2013

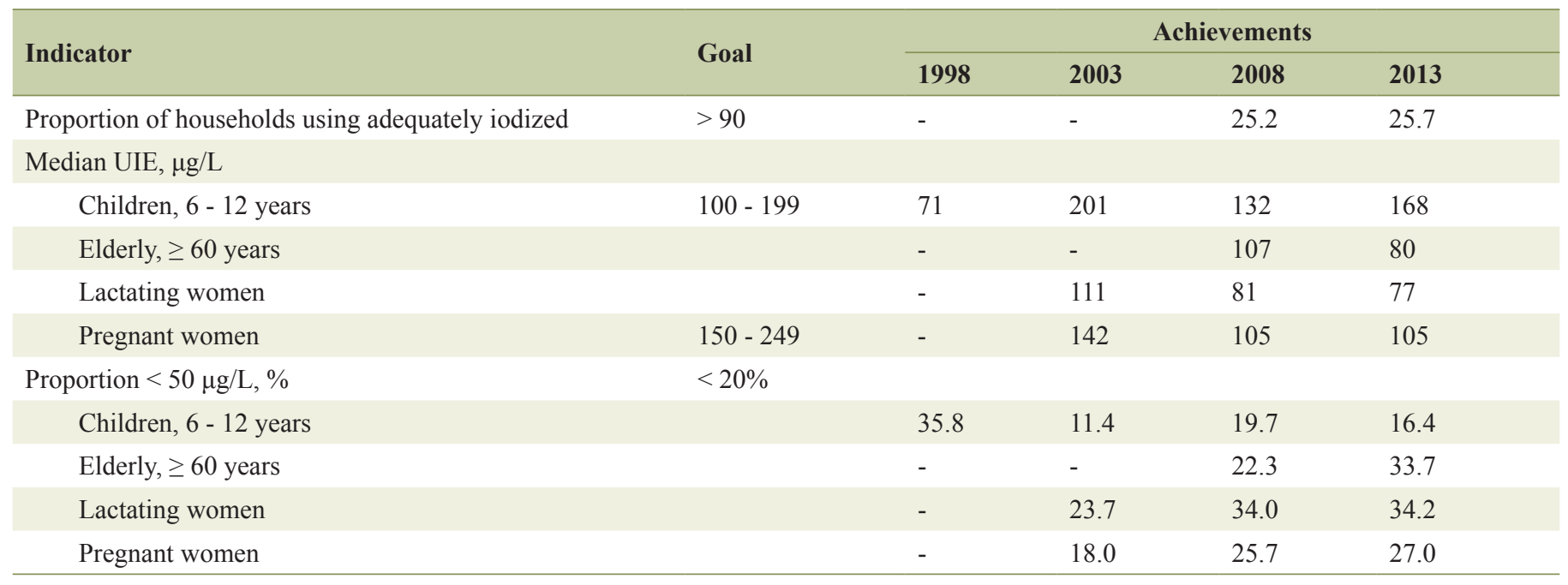

were found in the 2008 and 2013 NNSs with $1.3 \%$ and $2.8 \%$, respectively.

\section{Discussion}

The iodine status of SAC is recognized as a proxy of the iodine status of the entire population. However, results of surveys in the Philippines and in other countries prove otherwise. While iodine status of the preschool children has become optimal, the iodine status of the elderly, pregnant and lactating women has remained deficient. A study in China reported that median UI concentration of SAC tends to overestimate that of pregnant women and lactating women, but can be used for assessing iodine nutrition in the adult population [12]. Optimal iodine nutrition in SAC but mild-to-moderate iodine deficiency in their pregnant mothers were also reported in Thailand [13]. These mother-child pairs live in the same household and had meals together.

In a survey in Indonesia, the proportion of households with any iodized salt was high at $91.9 \%$, but the proportion with adequately iodized salt ( $>15 \mathrm{ppm}$ ) was thought to be low [14]. There was no mention of the actual proportion. Overall, results of the survey show optimum nutrition among the SAC, WRA and pregnant women. However, among the pregnant women, there was still iodine deficiency particularly among those in the lower socio-economic quintiles.

Household coverage of adequately iodized salt was increased by $6.1 \%$ (from $46.3 \%$ to $52.4 \%$ ) on average, from 2000 to 2010 , in 11 countries that included the Philippines [15]. In 2008, in the Philippines, median iodine content of household iodized salt was $5.28 \mathrm{ppm}$ and only $25.2 \%$ of the households surveyed had adequately iodized salt [16].

\section{Progress towards elimination of IDD}

The WHO/ICCIDD [3] has set certain indicators for moni- toring and evaluating IDD control programs. Sustainability indicators include a combination of median UI levels in the population, and availability of adequately iodized salt at the household level.

Since the implementation of the ASIN Law (RA 8172) in 1995 [1], iodine fortification level has been amended twice. The prescribed level of iodine in salt in the original law in 1995 was $\geq 40 \mathrm{ppm}$ at retail. This is higher than the international standard of $15 \mathrm{ppm}$. Three years after the implementation of the law, the first survey on IDD in 1998 showed median UIE of $71 \mu \mathrm{g} / \mathrm{L}$ and $35.8 \%$ had levels $<50 \mu \mathrm{g} / \mathrm{L}$, among SAC, still indicating "mild IDD" (Fig. 1 and Table 4). Eight years after the implementation of the ASIN Law, in the 2003 NNS, there was a drastic increase in UI among SAC, to $201 \mu \mathrm{g} / \mathrm{L}$. This level indicates an iodine intake that was "more than adequate", and it prompted a review of the law and fortification level was decreased in 2007 to 20 - 70 ppm across distribution channels, whether in bulk or retail, imported or local [17]. The decrease in the fortification level could have led to the corresponding lower UIE level of $132 \mu \mathrm{g} / \mathrm{L}$ obtained among SAC in the 2008 NNS. In 2013 [18], fortification level was again revised to 30 - $70 \mathrm{ppm}$ whether in bulk or retail. This optimum level of UIE was maintained in the 2013 NNS.

Similarly in China, the levels of iodine in their salt were also reduced when the medians of UI of SAC, at provincial level, were over $300 \mu \mathrm{g} / \mathrm{L}$ in 18 and 14 provinces in 1997 and 1999, respectively [19]. The initial iodization level was set at $50 \mathrm{mg} / \mathrm{kg}$ (50 ppm), in 1995 when USI was first implemented, then later reduced in 2000 to $35 \mathrm{ppm}$ after national monitoring by UI concentration showed this intake to be excessive.

Levels of iodine in iodized salt were determined in the 2008 and 2013 NNSs (Table 4). Proportion of households using adequately iodized salt was $25.2 \%$ and $25.7 \%$, respectively for the 2008 and 2013 NNSs. As an indicator for the elimination of IDD, these were below the goal of $90 \%$ of households using adequately iodized salt set by WHO/ICCIDD [3]. Results also showed the median iodine in salt was 5.3 and 5.6 ppm, respectively for the 2003 and 2013 NNSs. These results 
indicate the poor quality of iodized salt available.

The optimal UI level of SAC, in spite of the below standard concentration of iodine in the iodized salt, implies that there may be other sources of iodine in the diet of this group. Laboratory trials conducted on the retention of iodine in processed foods after cooking and storage showed encouraging results [20]. Substantial amount of iodine was retained in the iodized processed foods after cooking and during 3 months of storage. These processed foods can be good sources of iodine, since these are widely consumed by Filipino households. Iodized cooked processed food products can significantly contribute to the amount of consumption and consequently to the attainment of requirement of iodine.

The elderly, lactating women and pregnant women, may not be consuming enough iodine from other foods outside of that coming from iodized salt to satisfy their requirements. To ensure that optimal iodine nutrition is reached and sustained by all groups, monitoring of both iodized salt and intake of iodine should be done.

\section{Summary and conclusion}

Twenty years after the implementation of the ASIN Law, iodine status of SAC, aged 6 - 12 years old, is now optimal although pockets of deficiency still exist. IDD was still seen among the elderly, pregnant and lactating women. UIE levels corresponding to excessive intakes have steadily increased and should be given equal attention as this may cause adverse health consequences such as iodine-induced hyperthyroidism and autoimmune thyroid diseases.

\section{Acknowledgments}

Acknowledgement is due to Mr. Glen Melvin P. Gironella for statistical analysis of the data.

\section{Conflicts of Interest}

The authors declare no conflicts of interest.

\section{References}

1. Congress of the Philippines, Republic of the Philippines. Republic Act No. 8172. An Act Promulgating Salt Iodization Nationwide and for Related Purposes (ASIN LAW) and its Implementing Rules and Regulations.

2. ICCIDD. Global Scoreboard 2014: Number of iodine deficient countries more than halved in past decade. ICCIDD Newsletter. 2015.

3. WHO, UNICEF and ICCIDD. Assessment of Iodine Deficiency Disorders and Monitoring their Elimination. A guide for programme managers. Third Edition. 2007.

4. Wang Y, Zhang Z, Ge P, Wang S. Iodine deficiency disorders after a decade of universal salt iodization in a se- vere iodine deficiency region in China. Indian J Med Res. 2009;130(4):413-417.

5. Selamat R, Mohamud WN, Zainuddin AA, Rahim NS, Ghaffar SA, Aris T. Iodine deficiency status and iodised salt consumption in Malaysia: findings from a national iodine deficiency disorders survey. Asia Pac J Clin Nutr. 2010;19(4):578-585.

6. Yusuf HK, Rahman AM, Chowdhury FP, Mohiduzzaman M, Banu CP, Sattar MA, Islam MN. Iodine deficiency disorders in Bangladesh, 2004-05: ten years of iodized salt intervention brings remarkable achievement in lowering goitre and iodine deficiency among children and women. Asia Pac J Clin Nutr. 2008;17(4):620-628.

7. Aburto N, Abuduo M, Candelas V, Wu T. Effect and safety of salt iodization to prevent iodine deficiency disorders: A systematic review with meta-analysis. Geneva: World Health Organization. 2014.

8. DUNN JT, Crutchfield HE, Gutekunst R, Dunn AD. Methods for measuring iodine in urine. ICCIDD/UNICEF/ WHO. 1993.

9. Council for International Organizations of Medical Sciences (CIOMS). International Ethical Guidelines for Epidemiological Studies. 2008.

10. PCHRD-DOST. Philippine National Ethical Guidelines for Health Research. 2011.

11. International Council for Control of Iodine Deficiency Disorders (ICCIDD), United Nations Children's Fund (UNICEF) and World Health Organization (WHO). Assessment of Iodine Deficiency Disorders and Monitoring their Elimination. A guide for programme managers. Second Edition. 2001.

12. Liu P, Su X, Li M, Shen H, Yu J, Kelly PJ, Meng F, et al. Should urinary iodine concentrations of school-aged children continue to be used as proxy for different populations? Analysis of data from Chinese national surveys. Br J Nutr. 2016;116(6):1068-1076.

13. Gowachirapant S, Winichagoon P, Wyss L, Tong B, Baumgartner J, Melse-Boonstra A, Zimmermann MB. Urinary iodine concentrations indicate iodine deficiency in pregnant Thai women but iodine sufficiency in their school-aged children. J Nutr. 2009;139(6):1169-1172.

14. Atmarita KD, Soekirman AB, Izzwardy. Pregnant women in poor rural areas of Indonesia have low iodine intakes. IDD Newsletter. 2017. Excerpted from The situation of urinary iodine concentration (UIC) among school age children, women at reproductive age and pregnant women in Indonesia: the analysis of Riskesdas 2013. GIZI Indon. 2016;39(1):125-136.

15. Tran TD, Hetzel B, Fisher J. Access to iodized salt in 11 low- and lower-middle-income countries: 2000 and 2010. Bull World Health Organ. 2016;94:122-129.

16. Food and Nutrition Research Institute-Department of Science and Technology (FNRI-DOST) 2010. Philippine Nutrition Facts and Figures, 2008. DOST Complex, FNRI Bldg, Bicutan, Taguig City, Philippines.

17. Department of Health (DOH), Food and Drug Administration (FDA). Updated Standards for Iodine Level of Salt. Bureau Circular No. 2007-009. DOH, Philippines. 2007.

18. DOH, FDA. Amendment of Bureau Circular No. 2007- 
009 on the Standard Iodine Level of Salts for Strict Compliance of Iodized Salt Manufacturers or Processors. FDA Circular No. 2013-007. Philippines, 2013.

19. Wang Y, Zhang Z, Ge P, Wang S. Iodine status and thyroid function of pregnant, lactating women and infants (0-1 yr) residing in areas with an effective Universal Salt Iodi- zation program. Asia Pac J Clin Nutr. 2009;18(1):34-40.

20. Capanzana MV, Saises MC, Trinidad II TE, Garcia RG, Lapis TJ, Guevara MCP, Mercado FA, Lasan CDC. Retention of iodine in selected cooked food seasoned with iodized salt. Presented during the 32nd FNRI Seminar Series. 2006. 